\title{
DA ATUALIDADE DA SERVIDÃO VOLUNTÁRIA
}

\author{
ON THE CURRENTNESS OF VOLUNTARY SERVITUDE
}

Virgínia Fontes 1

Resumo Os processos de sujeição voluntária parecem consubstanciais à expansão do capitalismo. A transformação ocorrida no caráter da propriedade, tornando-a móvel e flexível, sob a forma dinheiro, tem sua contrapartida em nova mobilidade dos trabalhadores, expropriados do controle do conjunto do processo produtivo e tornados disponíveis como mera capacidade produtiva. A liberdade contemporânea não é mero engodo, pois expressa longa luta pela redução dos laços de controle de tipo senhorial, levada a efeito pelos camponeses e pelos trabalhadores urbanos. Mas também não pode ser considerada como expressão de uma real libertação humana, uma vez que repousa sobre formas de expropriação que, de maneira aparentemente 'natural', impõem aos trabalhadores sua própria sujeição. Na atualidade, o aprofundamento da separação realizada entre a propriedade econômica e as possibilidades de intervenção política agrava as condições dessa "servidão voluntária" e vem sendo, de forma quase sarcástica, apresentado como "trabalho voluntário".

Palavras-chave sujeição voluntária; liberdade; capitalismo; humanidade; abstração.
Abstract The processes of voluntary subjection seem consubstantial to the expansion of capitalism. The change that took place in the nature of property, making it mobile and flexible, under the form of money, has its counterpart in the new mobility of the workers, expropriated from the control of the productive control group and made available as a mere productive capacity. The contemporary freedom is not a mere enticement, for it expresses a long fight for the reduction of the manorial control ties, taken into effect by the peasants and by the urban workers. But it also can not be considered as an expression of actual human freedom, since it rests on forms of expropriation that, on an apparently 'natural' manner, impose to the workers their own subjection. Currently, the deepening of the of the separation that took place between the economic property and the possibilities of political intervention aggravates the conditions of this "voluntary servitude" and is being, on an almost sarcastic manner, presented as "voluntary work".

Key words voluntary subjection; freedom; capitalism; humanity; abstraction. 


\section{Da atualidade da servidão voluntária}

O texto de Adriana Geisler apresenta uma série de reflexões relevantes para a compreensão de questões ligadas ao processo pedagógico e à formação dos trabalhadores, a começar pelo contexto social no qual estes vêm sendo formados. Esta é, como sabemos, a condição fundamental para uma análise crítica do processo educativo: a compreensão das condições históricas nas quais se exercem a formação e a educação. Dentre os diversos temas que o artigo suscita, destacamos uma constatação que merece ser analisada com maiores detalhes, por sua relevância e atualidade: "Verifica-se que o não reconhecimento do trabalho como 'objetividade-subjetividade' é uma armadilha ideológica e, em nome dela, a produção da subjetividade dos trabalhadores vem sendo orientada no sentido da servidão voluntária".

Esta passagem assinala dois elementos, a indissociabilidade entre os aspectos objetivos e subjetivos do trabalho e a característica de servidão voluntária, que vem sendo extremamente reforçada no mundo contemporâneo. A separação estanque entre dois momentos (objetivo e subjetivo) da mesma existência tende a enfatizar ora o pólo de uma objetividade descarnada de humanidade - quando, por exemplo, a técnica é apresentada como se não derivasse de relações sociais -, ora o pólo de uma subjetividade exibida como se brotasse cristalinamente de uma individualidade apartada da vida social, desconsiderando-se o próprio processo de formação - histórico, social e intrapsíquico - dos seres singulares.

Dadas as limitações de espaço deste comentário, nos ateremos ao segundo elemento da citação: a servidão voluntária e sua íntima conexão com a própria lógica capitalista.

Os procedimentos que integram a relação social fundamental da extração do sobretrabalho sob a forma capitalista se recompõem em diferentes momentos históricos, apesar de modificados em sua aparência. Ainda que muitos de seus arautos procurem apresentar alguns aspectos como se fossem profundamente inovadores ou radicalmente 'transformados', 'modernizados', essa modernização apenas repõe, de forma atualizada, a forma especificamente capitalista de 'subalternizar' os trabalhadores e, portanto, de extrair sobretrabalho a partir da reprodução de trabalhadores livres. Procuramos, pois, rastrear a relação interna que une dois termos aparentemente excludentes - a servidão (a coerção, o constrangimento, a imposição) e a liberdade ${ }^{2}$.

Trata-se de problemática profundamente atual. Em parte, pela contradição que explicita, pela antinomia que expõe. O que significa e o que torna possível uma servidão voluntária? Tomando, pois, como mote a reflexão de Geisler sobre a servidão voluntária que vem marcando a vida dos trabalhadores contemporâneos, este texto objetiva contribuir para pensar as formas 
históricas do surgimento de tal contradição, de modo a auxiliar a compreensão de algumas configurações das formas sociais, objetivas e subjetivas, da vida contemporânea.

Diferentemente dos períodos anteriores, a construção histórica da liberdade contemporânea - na época capitalista - ocorreu por um duplo e contraditório processo. De um lado, a formação concreta da 'liberdade' dos trabalhadores consistiu (e consiste ainda) no processo que os separaria da propriedade efetiva, isto é, da capacidade de controlar a posse dos meios necessários para garantir sua sobrevivência. A expropriação do campesinato, entretanto, não pode ser limitada a um período anterior, 'primitivo', já pertencente a um remoto passado, pois continua ocorrendo em nossos dias (Harvey, 2004; Fontes, 2005). Segundo informes da Organização Mundial do Trabalho, o setor agrícola ainda ocupa metade da mão-de-obra mundial (Bureau International du Travail, 2006). Embora o mesmo documento não mencione detalhes sobre a situação desses trabalhadores, sabemos que a expansão urbana e industrial acompanha-se de forte redução do número de trabalhadores rurais, o que nos permite supor que boa parcela dessa população esteja ainda constituída por camponeses ou trabalhadores em condições similares. Observa-se, portanto, que prossegue um movimento contínuo de expropriação dos trabalhadores rurais, em especial nos países onde vastas parcelas camponesas vêm sendo 'urbanizadas' ou expropriadas (como China, Índia, Brasil e outros países da América Latina). A liberdade moderna - e contemporânea - começa, pois, com um processo concreto de brutal separação dos trabalhadores do que era, antes, sua propriedade ${ }^{3}$.

Entretanto, esse mesmo processo aproximaria a liberdade da noção de propriedade, mas, doravante, por um ângulo abstrato. A propriedade passaria a ser apresentada, de forma ideal, como a recompensa do trabalho. Os trabalhadores livres, isto é, despossuídos dos meios de assegurarem sua própria existência social, conservariam como sua propriedade fundamental o próprio ato criativo, a capacidade de produzir. A face real de tal idealização consistia em profunda separação no próprio ato social de criação, entre a capacidade de produzir e o acesso desses produtores à direção do conjunto do processo produtivo e, portanto, ao produto integral de seu trabalho. O argumento idealizado serviria simultaneamente para legitimar toda a propriedade existente até então, considerando-a como 'resultado de trabalho anterior', e para estreitar o acesso à propriedade dos frutos do trabalho por aqueles que exerciam o trabalho concreto, presente. Instaurava-se historicamente uma enorme cisão entre a propriedade efetiva, "abstraída", que controla e domina o processo produtivo, e o ato de concreto de produzir (tanto a produção de bens tangíveis como a de todas as necessidades, inclusive culturais e artísticas). Essas características continuam centrais em nossa sociedade, assim como a mencionada cisão, que a cada dia se aprofunda, ainda que mude de forma e de modalidade. 
Essa cisão permite compreender como o trabalho passava a ser definido intelectualmente - e apresentado socialmente - como o criador de todas as riquezas (como, por exemplo, por Locke, Smith ou Ricardo). Estimulavase o ato social (e individualizado) da produção, da criação, realçando-se a característica peculiar da vida humana de realizar, em seu breve percurso, algo que lhe ultrapassa, que lhe transcende. Entretanto, a 'propriedade fundamental' - a capacidade de decidir sobre o próprio processo produtivo e de dispor sobre os frutos do trabalho - seria doravante negado aos produtores diretos.

Como tal cisão ocorre, como se processa? Como é possível viver num mundo no qual ao mesmo tempo se é instado a criar, a agir, a produzir, a realizar algo para além da mera reprodução imediata, a contribuir, portanto, para uma coletividade social (cujas dimensões são variáveis, desde a família até à nação ou à própria noção de humanidade), e, simultaneamente, conviver com a 'despossessão', a expropriação sistemática dessa mesma capacidade?

A compreensão de tal procedimento, que converte liberdade em "servidão voluntária", supõe averiguarmos as formas históricas que o constituíram. A generalização do processo de mercantilização converteu todas as riquezas - e segue convertendo - em formas mobiliárias, móveis. Diferentemente dos processos sociais anteriores, a riqueza agora não mais se expressaria unicamente através dos bens imóveis (o que até então era expresso sobretudo através do controle da terra), mas pela capacidade de concentrar recursos para fazer atuar enormes quantidades do exercício produtivo, criador, criativo, isto é, de força de trabalho. A expansão e universalização do dinheiro, como forma social construída capaz de 'equivaler' a qualquer bem, diluía as formas fixas e estáveis da riqueza, deslocando-a para a capacidade de utilizar a força criativa da riqueza, o trabalho ${ }^{4}$. Ser rico - ser capitalista - tornava-se cada vez mais o atributo daqueles que podiam mobilizar as atividades produtivas humanas (ser 'capitão de indústria', industrial, como na figura dominante do século XIX, ou ser 'empreendedor', como na retórica contemporânea). No entanto, conservaram suas propriedades, inclusive as imobiliárias, dispondo da riqueza sob forma dupla: a parte criativa permanecia móvel (o capital, sob a forma dinheiro, capaz de empregar a força de trabalho, devendo ser permanentemente reinvestido), enquanto mantinham os estoques (e a suntuosidade) dos bens imóveis.

A expansão da riqueza sob sua forma móvel, não mais fixa, conserva uma estreita relação com a mobilidade da força de trabalho. Esta, de maneira similar, não mais deveria estar arraigada, atrelada a uma forma 'imóvel' de assegurar a sobrevivência. Essas formas imóveis não eram suficientemente impositivas para levar os trabalhadores a produzirem mais do que o necessário para reproduzirem aquele mesmo modo de vida, a partir de então considerado como mesquinho. O processo - originalmente europeu, mas tornado 
realidade em praticamente todo o mundo, sob formatos muito diferenciados - de expropriação da população camponesa, de cercamento dos campos para criação de ovelhas ou para a utilização da terra como uso suntuário (para caçadas, bosques privados, jardins) ou, ainda, através da apropriação das terras coletivas, resultaria na produção de trabalhadores também móveis, disponíveis para a atuação criativa, produtiva, onde quer que se localizasse o fulcro concentrado de meios para tal produção.

Estamos diante da produção histórica de trabalhadores doravante livres. Livres exatamente do quê? Livres, de forma mais precisa, para quê? Tratase de uma liberdade real ou apenas de uma liberdade fictícia? Esta liberdade constitui um mero engodo ou realmente houve alguma transformação histórica e ela incorporava também tensões oriundas dos próprios trabalhadores? Resultaria o processo de expropriação capitalista em situação pior do que uma escravidão aberta, ao tornar oculta a subordinação dos trabalhadores? $\mathrm{O}$ trabalhador livre moderno seria um enorme engano imposto às massas?

Ao analisarmos o processo histórico como propõe Marx, fugindo das modalidades reiterativas que se limitam a repetir citações, a compreensão do fenômeno permite abarcar sua complexidade. Segundo o próprio Marx, uma de suas mais importantes contribuições foi evidenciar o papel das lutas de classes no processo histórico. Ora, isso não significa que a todo momento encontramos formas organizadas de luta social, contrapondo, em bloco, o conjunto das 'classes dominadas' às 'classes dominantes'. Mas implica que a existência de classes sociais que dependem, para sua manutenção social, da extração de sobretrabalho de outras classes sociais produz necessariamente atritos e contradições, que se expressam de inúmeras maneiras.

Como compreender tais contradições? Poderemos encontrar elementos para responder a essa questão em Thompson (1989). O controle direto de proprietários de terra sobre os camponeses na Inglaterra era contestado por esses trabalhadores rurais, que, entretanto, resistiam fortemente a abandonar os vínculos com a terra. Sua resistência tenaz os predispunha a não abandonar a relação estreita com a terra. Nela encontravam seu sustento e sua vida e, assim, resistiram duplamente: às formas de controle hierárquico exercida pelos senhores das terras e às tentativas de expropriá-los dessas terras. Conservavam, assim, a lógica que predominava na vida social anterior (quando a riqueza equivalia à posse da riqueza mobiliária), ainda que na prática social resistissem a ela. Ainda que empenhados em luta legítima, não identificavam - nem poderiam - no processo de trabalho, propriedade deles mesmos, agora reduzido à uma nova forma 'móvel', o alvo das imposições patronais.

A resistência camponesa, diversas vezes, como mostra Thompson, aferrou-se a antigas tradições e manteve relações ambivalentes com os grandes proprietários, mas assegurou algumas conquistas e ampliou seu espaço de 
atuação. Não foi entretanto suficiente para impedir o avanço de sua transformação em trabalhadores disponíveis, libertados simultaneamente das relações pessoais com os proprietários de terra e do controle sobre o processo de trabalho.

Frente a eles, se contrapunha a tendência da propriedade móvel (capitalista) de tornar móveis todas as formas de propriedade. Inclusive a da terra, que se tornaria uma propriedade como as demais, vendável a quem tivesse mais 'bens mobiliários' (dinheiro ou equivalente) para adquiri-la, rentabilizá-la (através da utilização da força de trabalho) e dela se desfazer, quando estivesse exaurida ou improdutiva. Ressalte-se que o próprio critério de produtividade se alterava: seria improdutivo, a partir de então, tudo o que não mais servisse como base para uma força de trabalho apta a produzir mais sobretrabalho, a ser convertido em mais bens 'mobiliários', mais dinheiro, mais lucro. A produtividade descolava-se das necessidades concretas, como a de alimentar a população, para atrelar-se às exigências abstratas de valorização do próprio capital.

Nessa luta real operou-se uma transformação que nos permite compreender a peculiar característica social que lastreia o mundo contemporâneo - ao trabalhador restaria a propriedade de sua capacidade de dispor da própria atividade (a qual agora, descolada da terra que lhe permitia minorar sua necessidade, tornava-se totalmente móvel). Seria proprietário fundamentalmente de sua força de trabalho. Poderia, com o fruto de seu suor, tornar-se também proprietário de objetos específicos, segundo as diferentes conjunturas históricas. Poderia eventualmente vir a ser proprietário de uma casa, de um carro, de livros ou de uma televisão.

Ganharia a luta de tantos séculos, desvencilhando-se de senhores diretos. Mas ganharia tal luta perdendo em outro terreno. Tornava-se livre das imposições senhoriais diretas sobre seus deslocamentos, sua vida singular. Seria despossuído, entretanto, do controle da utilização da própria força de trabalho e dos resultados de sua atividade. Essa nova liberdade era, ao mesmo tempo, conquista e sujeição, e apontava, desde os primórdios, para a noção de servidão voluntária.

Ou de liberdade subjugada, se quisermos. Uma 'liberdade' grafada entre aspas, como o faz Marx ${ }^{5}$. Livre, sim, da coerção direta imposta pelos senhores da terra ou pelos regulamentos corporativos. Não poderiam tais trabalhadores sobreviver a não ser dispondo da única propriedade que lhes restara - e da qual eram, com razão, extremamente orgulhosos -, a capacidade de produzir o mundo.

Ora, a 'liberdade' que daí decorre não é, entretanto, apenas fictícia. Ela conserva de forma latente, permanentemente, a contradição que a atravessa. Na sua face negativa, ela é permanentemente a urgência, para os trabalhadores, de encontrar um comprador para sua única propriedade, sua força 
de trabalho. Premidos pela necessidade de sobreviver, gerações e gerações de trabalhadores se acotovelam em busca de 'empregos' ou equivalentes, de maneira a poderem assegurar sua própria existência. São impulsionados 'voluntariamente' à servidão, pela própria necessidade. Tornam-se móveis, migrantes, aglomeram-se nos bairros periféricos, disponíveis, assim como se aglomeravam na forma até aqui predominante da extração do sobretrabalho, a fabril, ao longo das jornadas de trabalho.

Entretanto, podem vislumbrar a face positiva dessa liberdade, a que decorre da evidência social de que somente a sua própria atividade cria o mundo que os serviliza e 'subalterniza' Ao longo dos séculos XIX e XX, não obstante, muitas vezes a luta dos trabalhadores concentrou-se em minorar a servitude, em assegurar melhores condições de vida, sobretudo pela garantia de direitos associados ao contrato de trabalho e pela tentativa de controlar o risco do desemprego. Em Thompson (1995), novamente encontramos o longo processo de aprendizado da classe trabalhadora no interior dessa nova forma de vida dominada pela lógica do capital, mas que, no entanto, a levaria a introjetar a dinâmica capitalista, estabelecendo uma dolorosa separação entre trabalho e vida, e a considerá-la como natural, nem sempre percebendo sua própria capacidade criativa.

Os trabalhadores também procuraram ativamente participar dos processos sociais de definição política, tentando incorporar-se, através da política, às formas de decisão coletiva sobre o processo de trabalho, procurando configurar sua organização por meio de regulamentações legais, além de lutar por maior acesso aos resultados desse trabalho. Através dos direitos de cidadania, procuraram reduzir o poder da propriedade abstrata sobre a vida concreta. Muitos autores chamaram a atenção para a possibilidade da socialização da política que aí se descortinava, vislumbrando a superação da cisão instaurada no âmago das relações sociais no capitalismo (Coutinho, 1994).

No entanto, a contradição é tenaz e se recompõe, evidenciando como tal cisão atravessa o conjunto da vida social. Como ressalta Wood, ela se reproduz também no terreno da política, onde a propriedade (e as decisões cruciais sobre o processo produtivo) são cuidadosamente separadas da decisão coletiva, apartadas do terreno da política. A democracia atual encontra aí os seus limites, através de 'blindagens' diversas, isolando as duas pontas da contradição: a propriedade abstrata e a humanidade real e concreta:

\footnotetext{
“Foi como um agregado desses indivíduos isolados, sem propriedade e roubados das solidariedades comunitárias, que a 'multidão trabalhadora' finalmente entrou para a comunidade de cidadãos. Evidentemente, a dissolução de identidades normativas tradicionais e de desigualdades jurídicas representou um avanço para esses indivíduos agora 'livre e iguais'; e a aquisição da cidadania conferiu a eles
} 
novos poderes, direitos e privilégios. Mas não se pode medir seus ganhos e suas perdas sem lembrar que o pressuposto histórico de sua cidadania foi a desvalorização da esfera política, a nova relação entre 'econômico' e 'político' que reduziu a importância da cidadania e transferiu alguns de seus poderes exclusivos para o domínio totalmente econômico da propriedade privada e do mercado (...). A desvalorização da cidadania decorrente das relações sociais capitalistas é atributo essencial da democracia moderna" (Wood, 2003, p. 182-183).

Neste novo século XXI, as conquistas anteriores que pareciam permitir espaços de certo alívio e de acomodação para os trabalhadores dos países centrais, configurando-se como uma espécie de aceno positivo para aqueles dos países periféricos, sofreram forte recuo e recolocam, portanto, no centro da cena social, a cisão contraditória que segue constituindo um dos eixos centrais da dinâmica capitalista: a servidão voluntária, recoberta na atualidade por caracterizações quase sarcásticas ${ }^{6}$.

A forma empresarial dominante na atualidade, de estímulo ao que chamam de 'trabalho voluntário' remete exatamente ao contrário do significado desta expressão. Expressa uma atividade sem remuneração regular, sem direitos associados ao trabalho, evidenciando a extrema necessidade na qual se encontra a maioria dos trabalhadores ${ }^{7}$. A necessidade converte-se na força impulsionadora da privação de liberdade, na sujeição 'voluntária'. Mostra, também, a estreita margem na qual se moviam os direitos tão duramente conquistados, desfigurados e crescentemente desqualificados na atualidade.

\section{Notas}

${ }^{1}$ Professora do Programa de Pós-Graduação em História da Universidade Federal Fluminense (UFF). Doutora em Filosofia pela Universidade Paris X. <vfontes@superig.com.br>

2 A liberdade, aliás, muitas vezes é concebida como se derivasse de uma natureza fixa da humanidade ou da própria vida social, 'deshistoricizada'. Por esse ângulo, a rigor, o termo não corresponderia ao seu conteúdo, uma vez que uma imposição natural ou social não corresponde a uma escolha livremente realizada.

${ }^{3}$ Ver, por exemplo, elementos sobre a situação da China contemporânea e a questão camponesa em Amin (2005), “O imperialismo, passado e presente”, especialmente as páginas 114 e 115 .

4 Este tema é magistralmente exposto em Marx (1985), no capítulo 1, "A mercadoria". Vale também ler o interessantíssimo trabalho de Hirschman (1979). 
5 No capítulo "A assim chamada acumulação primitiva", Marx afirma: "Assim, o movimento histórico, que transforma os produtores em trabalhadores assalariados, aparece, por um lado, como sua libertação da servidão e da coação corporativa (...). Por outro lado, porém, esses recém-libertados só se tornam vendedores de si mesmos depois que todos os seus meios de produção lhes foram roubados" (Marx, 1985, p. 262)

6 Ver, sobre o tema, o instigante livro de Boltanski e Chiapello, Le nouvel esprit du capitalisme (1999).

${ }^{7}$ Ver, sobre as formas atuais de generalização de práticas similares, Neves (2005).

\section{Referências}

AMIN, Samir. 2005. O imperialismo, passado e presente. Revista Tempo, v. 9, n. 18, p. 77-124.

BOLTANSKI, Luc; CHIAPELLO, Eve. 1999. Le nouvel esprit du capitalisme. Paris: Gallimard.

BUREAU INTERNATIONAL DU TRAVAIL. 2006. Le point sur l'agriculture. Disponível em: <www.ilo.org/public/french/ bureau/inf/download/wssd/pdf/agriculture.pdf $>$. Acesso em: 12 set. 2006.

COUTINHO, Carlos Nelson. 1994. Marxismo e política. São Paulo: Cortez.

FONTES, Virgínia. 2005. Reflexões im-pertinentes. Rio de Janeiro: Bom Texto.

HARVEY, David. 2004. O novo imperialismo. São Paulo: Loyola.

HIRSCHMAN, Albert O. 1979. As paixões e os interesses: argumentos políticos para o capitalismo antes de seu triunfo. Rio de Janeiro: Paz e Terra.

MARX, Karl. 1985. O capital. São Paulo: Nova Cultural, v. 1.

NEVES, Lucia Maria W. (org.). 2005. A nova pedagogia da hegemonia. São Paulo: Xamã.

THOMPSON, Edward P. 1989. Lucha de clases sin clases? In: THOMPSON, Edward P. (org.). Tradición, revuelta y consciencia de clase: estudios sobre la crisis de la sociedad preindustrial. $3^{\mathrm{a}}$ ed. Barcelona: Editorial Crítica.

1995. Tiempo, disciplina de trabajo y capitalismo industrial. In: THOMPSON, Edward P. (org.). Costumbres en comun. Barcelona: Editorial Crítica.

WOOD, Ellen M. 2003. Democracia contra capitalismo. São Paulo: Boitempo. 
